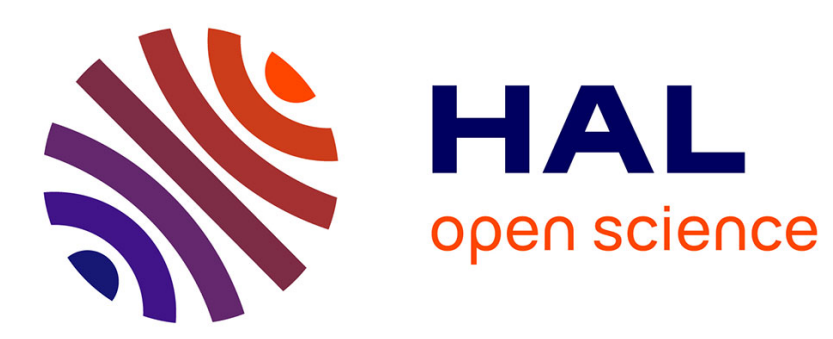

\title{
A HIGH PRESSURE INVESTIGATION OF THE CONDUCTION IN ILMENITE
}

\author{
C. Boekema, F. van Der Woude, G. Sawatzky
}

\section{To cite this version:}

C. Boekema, F. van Der Woude, G. Sawatzky. A HIGH PRESSURE INVESTIGATION OF THE CONDUCTION IN ILMENITE. Journal de Physique Colloques, 1976, 37 (C6), pp.C6-603-C6-606. 10.1051/jphyscol:19766125 . jpa-00216639

\section{HAL Id: jpa-00216639 https://hal.science/jpa-00216639}

Submitted on 1 Jan 1976

HAL is a multi-disciplinary open access archive for the deposit and dissemination of scientific research documents, whether they are published or not. The documents may come from teaching and research institutions in France or abroad, or from public or private research centers.
L'archive ouverte pluridisciplinaire HAL, est destinée au dépôt et à la diffusion de documents scientifiques de niveau recherche, publiés ou non, émanant des établissements d'enseignement et de recherche français ou étrangers, des laboratoires publics ou privés. 


\title{
A HIGH PRESSURE INVESTIGATION OF THE CONDUCTION IN ILMENITE
}

\author{
C. BOEKEMA and F. VAN DER WOUDE \\ Solid State Physics Laboratory, Materials Science Center, University of Groningen, Groningen
}

and

\section{G. A. SAWATZKY}

Laboratory for Physical Chemistry, Materials Science Center, University of Groningen, Groningen, The Netherlands

\begin{abstract}
Résumé. - On a étudié l'effet de la pression sur la conductibilité et les spectres Mössbauer du semiconducteur $\mathrm{FeTiO}_{3}$. Les spectres sont interprétés en termes de deux doublets. Le doublet, le plus intense est causé par les ions de fer dans les couches $\langle 111\rangle$ de fer; le deuxième est causé par les ions de fer dans les couches $\langle\mathbf{1 1 1}\rangle$ de titane dans la structure corundum. Nous comparons les changements, induits par la pression dans $\mathrm{FeTiO}_{3}$ aux changements dans $\mathrm{Fe}_{2} \mathrm{O}_{3}$, un isolateur, qui a la même structure. Nous expliquons l'augmentation de la conductibilité et la décroissance du déplacement isomérique des ions de fer dans les couches de fer par une délocalisation des électrons $3 d$ dans ces couches de $\mathrm{FeTiO}_{3}$.
\end{abstract}

Abstract. - The effect of pressure on the conductivity and the hyperfine interactions at the ${ }^{57} \mathrm{Fe}$ nuclei of semiconducting $\mathrm{FeTiO}_{3}$ has been studied. The Mössbauer spectra of ilmenite are interpreted in terms of two doublets. The most intense one is due to $\mathrm{Fe}^{2+}$-ions in the $\left.\mathrm{Fe}-<111\right\rangle$ layers; the second one is due to $\mathrm{Fe}^{2+}$-ions in the $\mathrm{Ti}-<111>$ layers in the corundum structure. A comparison is made with the pressure induced changes in insulating $\alpha-\mathrm{Fe}_{2} \mathrm{O}_{3}$ which has the same structure. The increase of conductivity and the decrease of the isomer shift of the $\mathrm{Fe}^{2+}$-ions in the Fe-layers of $\mathrm{FeTiO}_{3}$ is explained by means of a delocalization of $3 \mathrm{~d}$ electrons in these layers of ilmenite.

1. Introduction. - At high pressures the conductivity of semiconductors like ilmenite $\left(\mathrm{FeTiO}_{3}\right)$ may considerably change, due to the reduction of the lattice parameters and the related changes in the energy-band structure. Ilmenite, an antiferromagnet $\left(T_{\mathrm{N}}=57 \mathrm{~K}\right)$ has semiconducting properties, which can be described with a localized electron model [1,2]. Due to the extra 3d electron of the $\mathrm{Fe}^{2+}$ ions, ilmenite is a semiconductor, instead of an insulator like haematite $\left(\alpha-\mathrm{Fe}_{2} \mathrm{O}_{3}\right)$, showing the same corundum structure and which is also an antiferromagnet $\left(T_{\mathrm{N}}=956 \mathrm{~K}\right)$. Because of increasing overlap and transfer effects with increasing pressure, one may expect an increasing conductivity or even a nonmetal-metal transition in $\mathrm{FeTiO}_{3}$ under externally applied pressure. In view of these expectations, we have studied the effects of pressure on the conductivity and the hyperfine interactions at the ${ }^{57} \mathrm{Fe}$ nuclei in $\mathrm{FeTiO}_{3}$. In particular we have compared the pressure induced changes in the hyperfine interactions $\mathrm{FeTiO}_{3}$ and $\mathrm{Fe}_{2} \mathrm{O}_{3}$, because the $\mathrm{Fe}$ ions have nearly the same surroundings in both oxides and in this way we may have information about the behaviour of the extra 3d electron in $\mathrm{FeTiO}_{3}$ with pressure.
2. Structure. - Ilmenite has an ordered corundum structure [3] in which the $\mathrm{Fe}^{2+}$ and $\mathrm{Ti}^{4+}$ ions occupy alternating $<111>$ layers. The cations are located in a slightly distorted octahedron of oxygen ions. In figure 1 the cation sublattice of $\mathrm{FeTiO}_{3}$ is shown. No complete ordering of the $\mathrm{Fe}$ and $\mathrm{Ti}$ ions exists. A neutron diffraction study [4] revealed that about $5 \%$ of the $\mathrm{Fe}$ ions are located in the Ti- $\langle 111\rangle$ layers. The cationic puckering around the $<111\rangle$ basal planes, induced by the $\mathrm{Fe}^{2+}-\mathrm{Ti}^{4+}$ electrostatic repulsion is relatively large compared to the puckering in other compounds with corundum structure.

3. Experimental. - The high pressure apparatus which is used in the Mössbauer and conductivity measurements, is based upon the Bridgeman-anvil technique. The apparatus is similar in design as the high pressure system, described by $\mathbf{P}$. Debrunner et al. $[5,6]$. Mössbauer experiments are performed with the absorber in the pressure cell. The sample mixed with boron, is placed in a hole $(0.5 \mathrm{~mm} \varnothing)$ of a boron-epoxy disk ( $2 \mathrm{~mm} \varnothing, 0.35 \mathrm{~mm}$ thick). This disk, acting as a pressure vessel is pressurized between tungsten carbide anvils producing quasi hydrostatic 


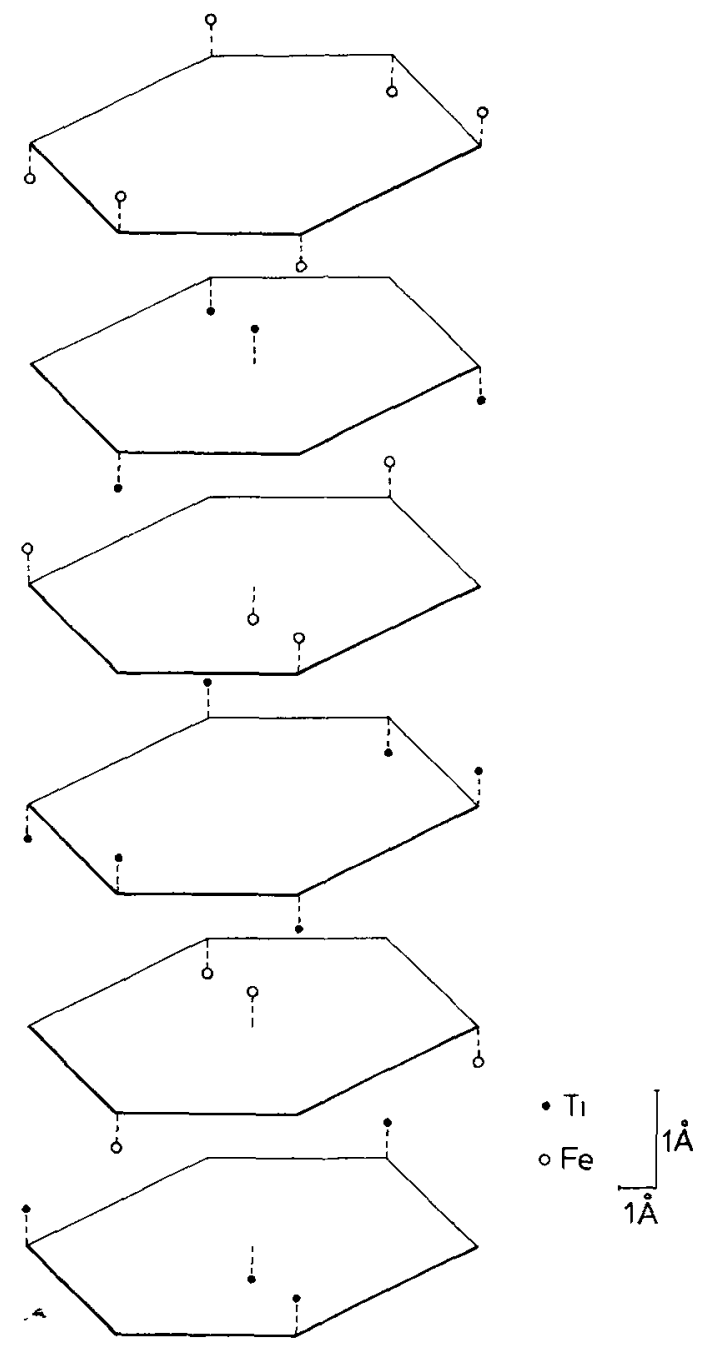

Fig. 1. - The cation sublattice of $\mathrm{FeTiO}_{3}$, showing the hexagonal unit cell.

pressure at the center of the disk. Before use the disk is prepressed in order to minimize the plastic deformation under pressure and to remove possible airbubbles in the boron-epoxy disk. By means of a manostat pressure regulator in conjunction with a pressure balance the pressure in the system could be kept constant for weeks, showing maximum deviations of about 2 kbar. Using a HP 3490 A multimeter we measure the resistance of the pressure cell, including the anvils and the sample gasket. The known standard resistance discontinuities for bismuth at $25.4 \mathrm{kbar}$ and $76 \mathrm{kbar}$ were used to calibrate the pressure apparatus.

Mössbauer spectra were recorded using a spectrometer in conjunction with an Intertechnique Didac 4000 multichannel analyser. A commercial pointsource of $45 \mathrm{mC}$ in a $\mathrm{Rh}$ matric with an active area of about $2 \mathrm{~mm}^{2}$ was used. The Mössbauer spectrometer was calibrated using absorbers of natural iron an powdered $\alpha-\mathrm{Fe}_{2} \mathrm{O}_{3}$ at room pressure. In order to maximize the Mössbauer absorption in the small samples in the pressure cell, we used enriched ${ }^{57} \mathrm{Fe}$-samples and most of the stray radiation was cut off by lead. Starting materials for the sample preparation were enriched or unenriched $\mathrm{Fe}_{2} \mathrm{O}_{3}, \mathrm{Fe}$ and $\mathrm{TiO}_{2}$. After being mixed in stoichiometric proportions, a pellet was made. The pellets were fixed at $1000^{\circ} \mathrm{C}$ for more than ten hours under vacuum in a quartz tube. The pellets were quenched to room temperature. The X-ray diffraction patterns of the unenriched samples showed only lines corresponding to the ilmenite structure. Spectra of the enriched and unenriched samples with about $5 \mathrm{mg} /$. $\mathrm{cm}^{2}{ }^{57} \mathrm{Fe}$ showed the same Mössbauer pattern.

4. Results. - We show in figure 2 the resistance of $\mathrm{FeTiO}_{3}$ as a function of quasihydrostatic pressure. The pressure scale is based upon calibration curves with $\mathrm{Bi}$. The curves are the best fits through the data points from several independent runs. As can be seen, up to about $20 \mathrm{kbar} \mathrm{FeTiO}_{3}$ shows a strongly decreasing resistance. At higher pressures the resistance is still decreasing but not as strong as in the first region of $20 \mathrm{kbar}$.

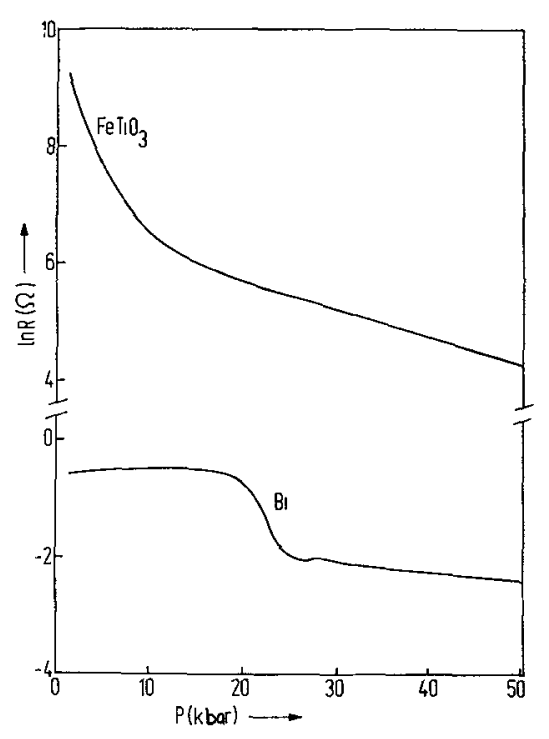

FIG. 2. - The resistance of $\mathrm{FeTiO}_{3}$ as a function of pressure at room temperature, together with the $\mathrm{Bi}$ calibration curve.

As has been mentioned before, some of the $\mathrm{Fe}$ ions in ilmenite are located in the Ti- $<111>$ layers. We interpret the spectra of $\mathrm{FeTiO}_{3}$ in terms of two doublets. The most intense doublet is due to $\mathrm{Fe}^{2+}$ ions in the $<111>$-Fe layers ; the other one is due to $\mathrm{Fe}^{2+}$ ions in the $\langle 111\rangle$ layers of $\mathrm{Ti}^{4+}$ ions. In figure 3 the room temperature spectrum of a thin absorber of $\mathrm{FeTiO}_{3}$ is shown, together with our interpretation. In Table $I$ the results of the analysis of room temperature spectra of $\mathrm{FeTiO}_{3}$ at 1 bar are given.

If one defines an ordening parameter $s$ as follows : let $\mathrm{f}$ be the fraction of $\mathrm{Fe}$ ions at the $\mathrm{Fe}<111>$ 


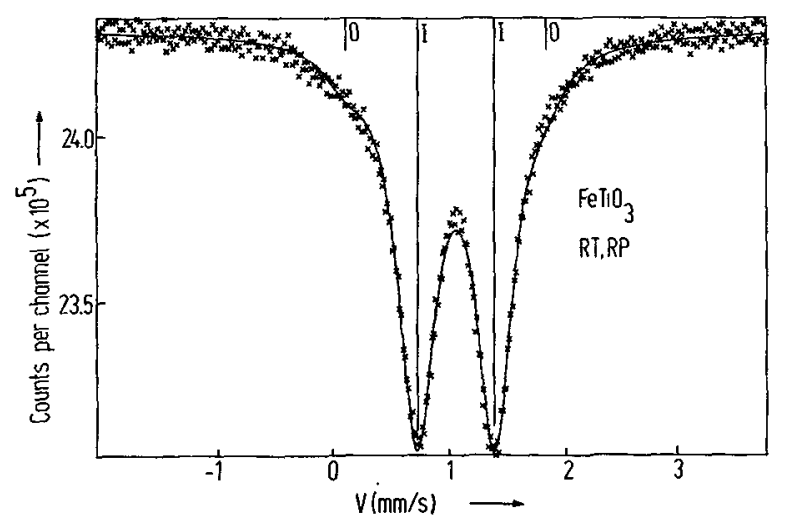

Frg. 3. - Mössbauer spectrum of $\mathrm{FeTiO}_{3}$ recorded at room pressure and room temperature.

layers, then we define $s \equiv 2 \mathrm{f}-1$. $s$ ranges from 1 for complete order and 0 for complete disorder. We find from our Mössbauer results (Table I) $s=0.88 \pm 0.01$ which is in good agreement with the result obtained by Shirane et al. : $s=0.90$ by means of a neutron diffraction study [4].

\section{TABLE I}

$\begin{array}{lcc}\text { Doublet notation } & \mathrm{I} & 0 \\ \text { IS rel to } \mathrm{Fe}(\mathrm{mm} / \mathrm{s}) & - & - \\ |2 \varepsilon|(\mathrm{mm} / \mathrm{s}) & 1.08 & 1.01 \\ \text { Relative intensity } & 0.69 & 1.78 \\ & 16.2 & 1\end{array}$

In figure 4 a Mössbauer spectrum of $\mathrm{FeTiO}_{3}$ is shown recorded at $14 \mathrm{kbar}$, together with our interpretation. The linewidth is of the order of $1 \mathrm{~mm} / \mathrm{s}$, due to the rather thick absorber in the pressure cell. If we

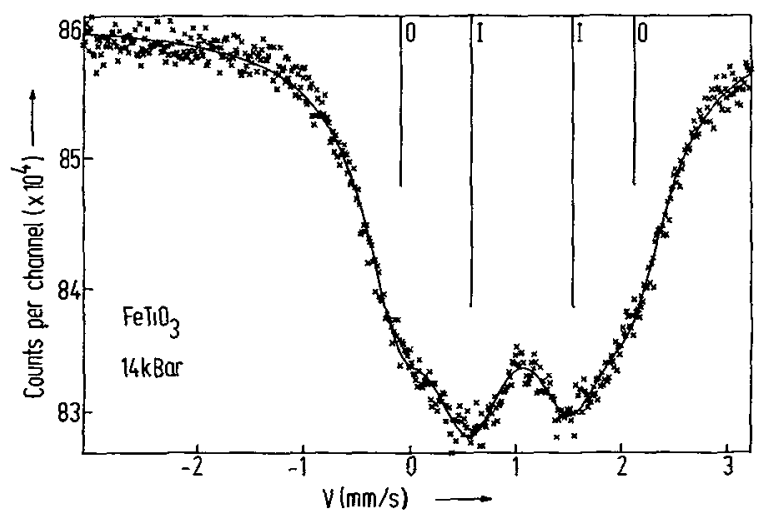

FIG. 4. - Mössbauer spectrum of $\mathrm{FeTiO}_{3}$ recorded at $14 \mathrm{kbar}$ and at room temperature.

interpret the high pressure Mössbauer spectra in terms of one doublet, we obtain reasonable agreement with Vaughan and Drickamer [7]. A better analysis is found in terms of two doublets as has been shown before. In figure 5 the hyperfine parameters $I S$ and $\varepsilon$ are given for these two doublets ( $I$ and 0 ) as a function of pressure. It can be seen that the isomer shift of the doublet (I) due to the Fe-ions in the Fe-layers decreases with about $0.06 \mathrm{~mm} / \mathrm{s}$ per $10 \mathrm{kbar}$ while the isomer

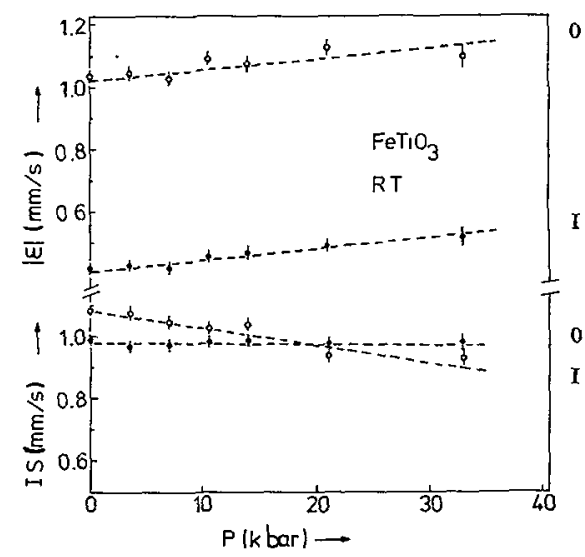

FIg. 5. - The isomer shift (rel to $\mathrm{Fe}$ ) and the absolute value of the quadrupole shift of the two doublets (I and 0 ) of $\mathrm{FeTiO}_{3}$ as a function of pressure obtained from spectra recorded at room temperature.

shift of doublet $(0)$ due to the $\mathrm{Fe}$ ions in the Ti-layers remains constant within the experimental error. It is interesting to compare this behaviour with the pressure induced changes in the hyperfine parameters of $\alpha-\mathrm{Fe}_{2} \mathrm{O}_{3}$, where the $\mathrm{Fe}$-ion has nearly the same surroundings. We have obtained Mössbauer spectra of $\alpha-\mathrm{Fe}_{2} \mathrm{O}_{3}$ up to $40 \mathrm{kbar}$. It is important to note that in this pressure range the isomer shift is constant within the experimental error

$$
(I S \text { rel to } \mathrm{Fe}=0.38 \mathrm{~mm} / \mathrm{s} \pm 0.01) \text {. }
$$

In figure 6 the quadrupole shift ( $\varepsilon$ ) is given as a function of pressure. At about $25 \mathrm{kbar}$ there is a change in sign of the quadrupole shift.

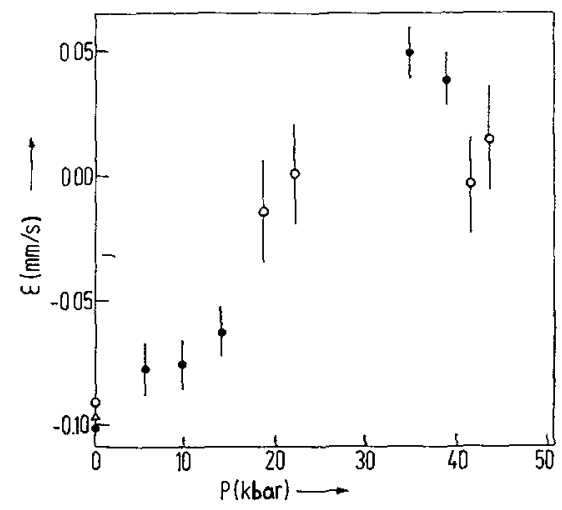

FIG. 6. $\rightarrow$ The quadrupole shift of $\mathrm{Fe}_{2} \mathrm{O}_{3}$ as a function of pressure obtained from spectra recorded at room temperature. Values obtained by Vaughan and Drickamer $([7],(O))$ and our results $((\bullet),(\Delta$ thin absorber)) are presented. 
5. Discussion. - The hyperfine interaction parameters like the isomer shift and the quadrupole interaction and their behaviour as a function of pressure, provide information concerning the electronic structure in semiconducting $\mathrm{FeTiO}_{3}$.

The quadrupole interaction, depending on the site-symmetry and geometry, structural properties of the iron sites, has two contributions : one ionic and one lattice contribution [8]. For the $\mathrm{Fe}^{3+}$ ions in the ${ }^{6} \mathrm{~S}_{5 / 2}$ state, which is the case for $\alpha-\mathrm{Fe}_{2} \mathrm{O}_{3}$, the ionic contribution is zero; the observed quadrupole splitting results from the lattice. The measured change in sign of the quadrupole splitting is associated with the Morin-transition in $\alpha-\mathrm{Fe}_{2} \mathrm{O}_{3}[7,9]$.

Concerning the $\mathrm{Fe}^{2+}$ ions in $\mathrm{FeTiO}_{3}$, the extra 3d electron will give rise to an ionic contribution to the quadrupole interaction, which is usually much larger than the lattice contribution. The electric field gradient at the ${ }^{57} \mathrm{Fe}$ nuclei caused by the extra electron reflects the deviation from cubic symmetry. The increase of the quadrupole splitting with pressure of the $\mathrm{Fe}^{2+}$ ions in the $\mathrm{Fe}$ and $\mathrm{Ti}$ layers in $\mathrm{FeTiO}_{3}$ indicate an increase of the site distortion, assuming no radial expansion of the $3 \mathrm{~d}$ orbitals with pressure [10]. A more detailed discussion can be given if the groundstates of the two different $\mathrm{Fe}^{2+}$ ions in the $<111>$-layers are better known.

Pressure induced changes in the isomer shift may have different causes. The isomer shift depends upon the $s$ electron charge at the ${ }^{57} \mathrm{Fe}$ nucleus. A change in the charge of $3 \mathrm{~d}$ character will effect the s electrons of the iron ions via Coulomb and exchange interactions [11]. The isomer shift is also related to covalency parameters such as overlap and transfer integrals, which depend upon the interionic distances [12]. Apart from a change in isomer shift also a pressure induced change in the second order Doppler shift is possible. A reasonable estimate of the change in shift of $\mathrm{Fe}_{2} \mathrm{O}_{3}$ due to a change in second order shift [7] and in covalency parameters [10] with pressure is about $-0.005 \mathrm{~mm} / \mathrm{s}$ per $10 \mathrm{kbar}$. This explains well the constancy of the isomer shift of the $\mathrm{Fe}^{3+}$ ions in $\mathrm{Fe}_{2} \mathrm{O}_{3}$, because no change in charge of $3 \mathrm{~d}$ character with pressure can be expected. Concerning the behaviour of the isomer shift of the Fe-ions in the $\mathrm{Fe}$ layers with pressure, we think that the decrease of $0.06 \mathrm{~mm} / \mathrm{s}$ per $10 \mathrm{kbar}$ is mostly due to an increase of the $s$ electron density at the ${ }^{57} \mathrm{Fe}$ nuclei. Assuming that the extra $3 \mathrm{~d}$ electron of the $\mathrm{Fe}^{2+}$-ion in the $\mathrm{Fe}$ layer becomes delocalized with increasing pressure, we can say that the $s$ electrons are less screened from the nucleus, causing an increase of $s$ electron density at the ${ }^{57} \mathrm{Fe}$ nucleus. In this way it is easy to see why the isomer shift of the Fe-ions in the Ti-layers is constant with pressure : the extra $3 \mathrm{~d}$ electrons are well localized in the $\mathrm{Ti}^{4+}$-layers in comparison with those in the $\mathrm{Fe}^{2+}$-layers. This delocalization process in the $\mathrm{Fe}-$ layers will also explain the increase of conductivity of ilmenite with pressure.

6. Conclusion. - Up to about $20 \mathrm{kbar}, \mathrm{FeTiO}_{3}$ shows a strongly increasing conductivity. This fact and the high pressure Mössbauer spectra of semiconducting $\mathrm{FeTiO}_{3}$ can be interpreted in terms of a charge delocalization process of the $\mathrm{Fe}^{2+}$-ions in the $\mathrm{Fe}-<111>$ layers. This interpretation results from a comparison of the high pressure Mössbauer data of insulating $\mathrm{Fe}_{2} \mathrm{O}_{3}$.

Acknowledgements. - The authors wish to thank Dr. C. Blaauw and Dr. R. L. Ingalls for setting up the high pressure-Mössbauer apparatus. We also acknowledge the helpfull suggestions of Dr. S. Bukshpan.

This work is part of the research program of the «Stichting voor Fundamenteel Onderzoek der Materie " (F. O. M.) and has been made possible by financial support from the "Nederlandse Organisatie voor Zuiver Wetenschappelijk Onderzoek » (Z. W. O.).

\section{References}

[1] Goodenough, J. B. and Sticker, J. J., Phys. Rev. 164 (1967) 768.

[2] JoNKER, G. H. and van Houten, S., Halbleiterprobleme 6 (1961) 118

[3] Wyckoff, R. W., Crystal Structures (New York : Interscience), vol. 2, 420, 1965.

[4] Shirane, G., Pickart, S. J., Nathans, R. and Ishikawa, Y., J. Phys. Chem. Solids 10 (1959) 35.

[5] Debrunner, P., Vaughan, R. W., Champion, A. R., Cohen, J., MoYris, J. and Drickamer, H. G., Rev. of. Sci. Instrum. 37 (1966) 1310.

[6] Holzapfel, W. B., C. R. C. (Critical Rev. in Solid State Sciences) page 89 (1975).
[7] Vaughan, R. W. and Drickamer, H. G., J. Chem. Phys. 47 (1967) 1530.

[8] Ingalls, R. L., Phys. Rev. 133A (1964) 787.

[9] Worlton, T. G. and Decker, D. L., Phys. Rev. 171 (1968) 596.

[10] Boekema, C., Van Der Woude, F. and Sawatzky, G. A., Phys. Rev. 11 (1975) 2705.

[11] Greenwood, N. N. and GibB, T. C., Mössbauer Spectroscopy (Chapman and Hall Ltd., London) 1971.

[12] Sawatzky, G. A. and VAN Der Woude, F., J. Physique, Colloq. 35 (1974) C 6-47. 